\title{
Estradiol-Induced Enhancement of Object Memory Consolidation Involves Hippocampal Extracellular Signal- Regulated Kinase Activation and Membrane-Bound Estrogen Receptors
}

\author{
Stephanie M. Fernandez, ${ }^{1 \star}$ Michael C. Lewis, ${ }^{1 \star}$ Angela S. Pechenino, ${ }^{1}$ Lauren L. Harburger, ${ }^{1}$ Patrick T. Orr, ${ }^{1}$ \\ Jodi E. Gresack, ${ }^{1}$ Glenn E. Schafe, ${ }^{1,2}$ and Karyn M. Frick ${ }^{1,2}$ \\ ${ }^{1}$ Department of Psychology and ${ }^{2}$ Interdepartmental Neuroscience Program, Yale University, New Haven, Connecticut 06520
}

\begin{abstract}
The extracellular signal-regulated kinase (ERK) pathway is critical for various forms of learning and memory, and is activated by the potent estrogen $17 \beta$-estradiol $\left(\mathrm{E}_{2}\right)$. Here, we asked whether $\mathrm{E}_{2}$ modulates memory via ERK activation and putative membrane-bound estrogen receptors (ERs). Using ovariectomized mice, we first demonstrate that intraperitoneal injection of $0.2 \mathrm{mg} / \mathrm{kg} \mathrm{E} \mathrm{E}_{2}$ significantly increases dorsal hippocampal levels of phosphorylated ERK protein $1 \mathrm{~h}$ after injection. Second, we show that $\mathrm{E}_{2}$ administered intraperitoneally $(0.2 \mathrm{mg} / \mathrm{kg})$ or via intrahippocampal infusion $(5.0 \mu \mathrm{g} / \mathrm{side})$ immediately after training in an object recognition task significantly enhances memory retention, and that the beneficial effect of intraperitoneal $\mathrm{E}_{2}$ is blocked by dorsal hippocampal inhibition of ERK activation. Third, using bovine serum albumin-conjugated $17 \beta$-estradiol $\left(B S A-E_{2}\right)$, we demonstrate that $\mathrm{E}_{2}$ binding at membrane-bound ERs can increase dorsal hippocampal ERK activation and enhance object memory consolidation in an ERK-dependent manner. Fourth, we show that this effect is independent of nuclear ERs, but is dependent on the dorsal hippocampus. By demonstrating that $\mathrm{E}_{2}$ enhances memory consolidation via dorsal hippocampal ERK activation, this study is the first to identify a specific molecular pathway by which $\mathrm{E}_{2}$ modulates memory and to demonstrate a novel role for membrane-bound $\mathrm{ERs}$ in mediating $\mathrm{E}_{2}$-induced improvements in hippocampal memory consolidation.
\end{abstract}

Key words: estrogen; memory; ERK; MAPK; hippocampus; receptor

\section{Introduction}

Although estrogens can influence memory and hippocampal function, the molecular mechanisms underlying estrogeninduced effects on memory remain mostly unknown. Such mechanisms are difficult to discern using experimental designs in which estrogens are given before training because circulating estrogens can affect nonmnemonic aspects of task performance such as motivation, anxiety, and motor function. As such, experiments that administer a rapidly metabolized form of the potent estrogen, $17 \beta$-estradiol $\left(\mathrm{E}_{2}\right)$, immediately after training ("posttraining") and test retention after $\mathrm{E}_{2}$ is metabolized, allow for effects on memory consolidation to be measured in the absence of such nonmnemonic confounds. In female rodents, posttrain-

Received April 25, 2007; revised June 25, 2008; accepted July 16, 2008.

This work was supported by Yale University and National Institute of Mental Health (NIMH) Grant MH065460 and National Institute on Aging Grant AG022525 (K.M.F.). Stipend support to S.M.F. was provided by an American Psychological Association Diversity Program in Neuroscience fellowship (NIMH T32 MH18882). We thank Jessica Falco for assistance with behavioral testing, and Virginia Rogers, Raymond Nagem, Lawrence Moy, Lana Verkuil, and Kenneth Kato for assistance with histology.

*S.M.F. and M.C.L. contributed equally to this work.

Correspondence should be addressed to Dr. Karyn M. Frick, Department of Psychology, Yale University, P.0. Box 208205, New Haven, CT 06520. E-mail: karyn.frick@yale.edu.

DOI:10.1523/JNEUROSCI.1968-08.2008

Copyright $\odot 2008$ Society for Neuroscience $\quad$ 0270-6474/08/288660-08\$15.00/0 ing $\mathrm{E}_{2}$ enhances memory consolidation in spatial Morris water maze and object recognition tasks (Packard and Teather, 1997a,b; Gresack and Frick, 2006).

The effects of posttraining $E_{2}$ on memory may be mediated via multiple estrogen receptor (ER) mechanisms in the brain. Traditional "genomic" mechanisms involve $\mathrm{E}_{2}$ binding to nuclear estrogen receptors (ER $\alpha$ and $\mathrm{ER} \beta$ ) and subsequent binding of the ER complex to estrogen response elements on DNA, which initiates gene transcription. $\mathrm{E}_{2}$ may also bind to postulated membrane-bound ERs (Razandi et al., 1999; Watson et al., 1999b), including one referred to as ER-X (Toran-Allerand, 2005), to produce rapid "nongenomic" effects, including activation of cytoplasmic signaling cascades. Importantly, $\mathrm{E}_{2}$ can affect memory consolidation within $2 \mathrm{~h}$ after training (Luine et al., 2003), suggesting that $E_{2}$ effects involve rapid membrane-bound ER-mediated activation of intracellular signaling cascades.

Activation of the extracellular signal-regulated kinase/ mitogen-activated protein kinase (ERK/MAPK) signaling cascade in the hippocampus is critical for several types of memory consolidation (Atkins et al., 1998; Blum et al., 1999; Schafe et al., 2000; Kelly et al., 2003; Runyan et al., 2004), and blocking hippocampal ERK activation by inhibiting mitogen-activated protein kinase kinase (MEK) (the kinase that activates ERK) impairs memory consolidation in several tasks (Blum et al., 1999; Walz et 
al., 2000; Runyan et al., 2004; Zhang et al., 2004). In particular, intracerebroventricular MEK inhibition also disrupts object memory consolidation (Bozon et al., 2003; Kelly et al., 2003). $\mathrm{E}_{2}$ increases ERK activation in the hippocampus in vivo and in vitro, and this effect is blocked by MEK inhibition (Kuroki et al., 2000; Nilsen and Brinton, 2003; Yokomaku et al., 2003). However, no study has examined whether the ability of $\mathrm{E}_{2}$ to facilitate memory consolidation is dependent on ERK activation.

Therefore, the goals of this study were to determine (1) whether hippocampal ERK activation is necessary for $E_{2}$ to enhance hippocampal memory consolidation, and (2) whether membrane-bound ERs are involved in estrogenic modulation of hippocampal memory consolidation and ERK activation. We first show that $\mathrm{E}_{2}$ increases dorsal hippocampal ERK activation. Using an object recognition task in which hippocampal involvement has been demonstrated (Clark et al., 2000; Baker and Kim, 2002), we next show that $\mathrm{E}_{2}$-induced enhancement of object memory consolidation is dependent on dorsal hippocampal ERK activation, and can involve membrane-bound ERs. This study is the first to identify a specific molecular pathway underlying the beneficial effects of $\mathrm{E}_{2}$ on memory and demonstrate involvement of membrane-bound ERs in $\mathrm{E}_{2}$-induced enhancement of hippocampal memory consolidation.

\section{Materials and Methods}

Subjects. Female C57BL/6 mice were obtained from Taconic Farms or The Jackson Laboratory at 9-12 weeks of age. Mice were handled briefly before use. Five mice per cage were housed in a room with a $12 \mathrm{~h}$ light/ dark cycle. Food and water were provided ad libitum. Procedures followed the National Institutes of Health Guide for the Care and Use of Laboratory Animals and were approved by the Yale University Animal Care and Use Committee.

Drugs and infusions. Cyclodextrin-encapsulated $\mathrm{E}_{2}$ (Sigma-Aldrich) at a dose of $0.2 \mathrm{mg} / \mathrm{kg}$ was dissolved in physiological saline in a volume of 4 $\mathrm{ml} / \mathrm{kg}$, and injected intraperitoneally. This dose in mice facilitates object memory consolidation in the task used here (Gresack and Frick, 2004, 2006 ). The vehicle, hydroxypropyl- $\beta$-cyclodextrin (HBC), was dissolved in an equal volume of saline and contained the same amount of cyclodextrin as $\mathrm{E}_{2}$. The MEK inhibitor $\alpha$-[amino[(4-aminophenyl)thio]methylene]-2-(trifluoromethyl)benzeneacetonitrile (SL327) (SigmaAldrich), at a dose of $30 \mathrm{mg} / \mathrm{kg}$, was dissolved in 100\% dimethyl sulfoxide (DMSO) and injected intraperitoneally in a volume of $2.0 \mathrm{ml} / \mathrm{kg}$. Vehicle controls received $\mathrm{HBC}$ or both $\mathrm{HBC}$ and DMSO. For intrahippocampal infusions, physiological saline or cyclodextrin-encapsulated $\mathrm{E}_{2}$ dissolved in physiological saline $(5.0 \mu \mathrm{g} / 0.5 \mu \mathrm{l})$ was infused at 0.5 $\mu \mathrm{l} / \mathrm{min}$ for $1 \mathrm{~min}$.

To demonstrate that $\mathrm{E}_{2}$-induced increases in object recognition were dependent on dorsal hippocampal ERK activation, other mice received intrahippocampal infusions of vehicle or the MEK inhibitor 1,4-diamino2,3-dicyano-1,4-bis (o-aminophenylmercapto)butadiene (U0126) (2.0 $\mu \mathrm{g} / \mu \mathrm{l}$; Sigma-Aldrich) concurrently with intraperitoneal $\mathrm{E}_{2}$ injection or intracerebroventricular infusion of bovine serum albumin-conjugated $17 \beta$-estradiol (see below) into the dorsal third ventricle. U0126 was dissolved in $100 \%$ DMSO to $4 \mu \mathrm{g} / \mu \mathrm{l}$ as a stock solution and then serially diluted in physiological saline for infusion of various doses. U0126 or vehicle (50\% DMSO) were infused at a rate of $0.50 \mu \mathrm{l} / \mathrm{min}$ and a volume of $0.50 \mu \mathrm{l} /$ side. Other mice received intracerebroventricular infusions of vehicle or bovine serum albumin-conjugated $17 \beta$-estradiol [ $\beta$-estradiol 6-(O-carboxy-methyl)oxime] (BSA-E $)_{2}$ (Sigma-Aldrich). The covalent conjugation of $\mathrm{E}_{2}$ to the large BSA molecule prevents $\mathrm{E}_{2}$ from passing through the cell membrane and binding to intracellular ERs (Taguchi et al., 2004). Thus, effects of BSA- $E_{2}$ should be mediated by membranebound ERs. BSA- $\mathrm{E}_{2}$ was dissolved in Tris- $\mathrm{HCl}$ to a concentration of 5.0 $\mu \mathrm{M}$. Either $5.0 \mu \mathrm{M} \mathrm{BSA}-\mathrm{E}_{2}$ or vehicle (Tris- $\mathrm{HCl}$ ) was infused at a rate of $0.5 \mu \mathrm{l} / \mathrm{min}$ at a volume of $1.0 \mu \mathrm{l}$.

To demonstrate that the effects of BSA-E $\mathrm{E}_{2}$ on memory and ERK acti- vation were independent of nuclear estrogen receptors, other mice received intracerebroventricular infusions of BSA- $\mathrm{E}_{2}$ conducted as described above concurrently with intrahippocampal infusions of the nuclear estrogen receptor antagonist (7a,17b)-7-[9[(4,4,5,5,5pentafluoropentyl)sulfinyl]nonyl] estra-1,3,5(10)-triene-3,17-diol (ICI 182,780) (10 $\mu \mathrm{g} / \mu \mathrm{l}$; Sigma-Aldrich). ICI 182,780 is an antagonist of ER $\alpha$ and $\mathrm{ER} \beta$ that impairs $\mathrm{E}_{2}$-induced ER dimerization (Weatherman et al., 2002) and translocation of ERs into the cell nucleus (Dauvois et al., 1993). If ICI 182,780 does not block the effects of BSA-E $E_{2}$ on memory and ERK activation, then this would indicate that these effects are mediated by membrane-associated estrogen receptors rather than nuclear receptors. Intrahippocampal infusions of ICI 182,780 were conducted at a rate of $0.5 \mu \mathrm{l} / \mathrm{min}$ and a volume of $0.5 \mu \mathrm{l} /$ side, resulting in a dose of 5.0 $\mu \mathrm{g} / \mathrm{side}$. In other mice, ICI 182,780 was infused intrahippocampally without concurrent intracerebroventricular infusion as a control because of a report that this compound in female rats can act as an estrogen receptor agonist to enhance place learning when administered in the absence of $\mathrm{E}_{2}$ (Zurkovsky et al., 2006). To compare effects of ICI 182,780 with those of traditional $\mathrm{E}_{2}, 0.2 \mathrm{mg} / \mathrm{kg} \mathrm{E} \mathrm{E}_{2}$ was administered intraperitoneally either alone or with ICI 182,780 infused intrahippocampally. The $\mathrm{E}_{2}$ plus intrahippocampal ICI 182,780 group also served as a control for the effectiveness of the ICI compound in blocking the effects of traditional, non-BSA-conjugated $\mathrm{E}_{2}$ on object memory consolidation and ERK activation. Vehicle controls for the aforementioned groups received intracerebroventricular and intrahippocampal infusions of saline or BSA dissolved in saline.

Finally, to demonstrate that the effects of BSA- $\mathrm{E}_{2}$ on memory and ERK activation involved the dorsal hippocampus, $\mathrm{BSA}-\mathrm{E}_{2}$ was infused bilaterally into the dorsal hippocampus of another set of mice. Intrahippocampal infusions were conducted at a rate of $0.5 \mu \mathrm{l} / \mathrm{min}$ and at a volume of $0.5 \mu \mathrm{l} / \mathrm{side}$, resulting in doses of $5.0 \mu \mathrm{m}$ per side. As a control, these mice also received intracerebroventricular infusions of vehicle (BSA dissolved in saline). Additional mice received intracerebroventricular BSA-E 2 plus intrahippocampal vehicle as a control to replicate the effects of intracerebroventricular BSA- $\mathrm{E}_{2}$ observed above. As an additional method of demonstrating hippocampal involvement in the BSA- $E_{2}$ effect, other mice received intracerebroventricular infusions of BSA- $E_{2}$ conducted as described above concurrently with intrahippocampal infusions of the $\mathrm{GABA}_{\mathrm{A}}$ receptor agonist 3-hydroxy-5-aminomethylisoxazole (muscimol) $(0.50 \mu \mathrm{g} / \mu \mathrm{l}$ dissolved in saline; Sigma-Aldrich). Muscimol temporarily inactivates a brain region of interest by increasing GABAergic inhibition without permanently damaging the tissue (Martin, 1991). Therefore, if muscimol interferes with the beneficial effects of intracerebroventricular BSA- $E_{2}$ on memory, then this would suggest critical involvement of the dorsal hippocampus in this effect. Intrahippocampal infusions of muscimol were conducted at the same rate and volume as above. Vehicle controls for all of the aforementioned groups received intracerebroventricular and intrahippocampal infusions of saline or BSA dissolved in saline.

Injection cannulas for intrahippocampal and intracerebroventricular infusions remained in place for $1 \mathrm{~min}$ after infusion to prevent drug diffusion up the injection track. For behaviorally tested mice, all solutions were administered immediately after the sample phase of object recognition training.

Surgery. Mice were ovariectomized and implanted with intracranial guide cannulas as described previously (Lewis et al., 2008). Mice receiving intracranial infusions were implanted with stainless-steel guide cannulas (Plastics One) aimed at the dorsal hippocampus (bilaterally), dorsal third ventricle, or both loci. Mice were anesthetized with isoflurane gas (5\% for induction, $2 \%$ for maintenance). Using a stereotaxic apparatus (Kopf Instruments), guide cannulas (C232GC; 26 gauge; Plastics One) with inserted dummy cannulas (C232DC) were directed toward the hippocampus $[-1.7 \mathrm{~mm}$ posterior to bregma, $\pm 1.5 \mathrm{~mm}$ lateral to midline, $-2.3 \mathrm{~mm}$ (injection site) ventral to skull surface], dorsal third ventricle $[-0.5 \mathrm{~mm}$ posterior to bregma, \pm 0.0 lateral to the midline, -3.0 (injection site) ventral to the skull surface], or both the hippocampus and dorsal third ventricle (triple guide; same coordinates as above for both regions) (Paxinos and Franklin, 2001). Each cannula was fixed to 
the skull with dental cement that also served to close the wound. Mice recovered for at least $5 \mathrm{~d}$ before testing.

During drug infusions, mice were gently restrained. Dummy cannulas were replaced with injection cannulas (C232I; intrahippocampal: 26 gauge, extending $0.8 \mathrm{~mm}$ beyond the $1.5 \mathrm{~mm}$ guide; intracerebroventricular: 28 gauge, extending $1.0 \mathrm{~mm}$ beyond the $2.0 \mathrm{~mm}$ guide) attached to polyethylene tubing (PE50) connected to a $10 \mu \mathrm{l}$ Hamilton syringe. Infusions were controlled by a microinfusion pump (KDS 100; KD Scientific).

Histology. Behaviorally tested mice receiving intracranial infusions were cervically dislocated. Brains were immediately removed and stored in $10 \%$ formalin until sectioning. Coronal sections $(60-\mu \mathrm{m}$-thick collected proximal to cannula tracts) were cut on a cryostat $\left(-18^{\circ} \mathrm{C}\right)$, slides were stained with cresyl violet, and injection sites were verified by light microscope. Only mice with correct placements (supplemental Figs. 1-3, available at www.jneurosci.org as supplemental material) were included in statistical analyses.

Western blotting. One hour after systemic injection or $5 \mathrm{~min}$ after intracranial infusion, mice were decapitated and the dorsal hippocampus was immediately dissected bilaterally on ice. For some mice (see Fig. $4 b$ ), tissue punches of the CA1 region of the dorsal hippocampus, rather than the entire dorsal hippocampus, were taken to focus analysis on a hippocampal subregion that is extremely sensitive to the effects of $E_{2}$ (for review, see Woolley, 2007). CA1 tissue punches $(1 \mathrm{~mm}$; Fine Science Tools) were taken from $480-\mu \mathrm{m}$-thick fresh frozen sections cut on a microtome. All tissue samples were resuspended 1:50 w/v in lysis buffer and homogenized with a probe sonicator. Western blotting was conducted as previously described (Lewis et al., 2008). Blots were incubated with anti-phospho-p44/42 MAPK (Thr202/Tyr204) (1:1000; Cell Signaling Technology) or an anti-total p44/42 MAPK antibody (1:2000; Cell Signaling Technology) overnight. Densitometry was conducted using Kodak 1D 3.6 software on the Kodak Image Station 440 CF. Phosphop42/p44 ERK levels were normalized to total p42/p44 ERK levels.

Object recognition. The object recognition task, conducted as previously reported (Fernandez and Frick, 2004), assessed nonspatial hippocampal-dependent memory (Clark et al., 2000; Baker and Kim, 2002). Mice were habituated by allowing them to freely explore an empty white box for $5 \mathrm{~min}$. No data were recorded. Twenty-four hours later, mice were rehabituated for $1 \mathrm{~min}$, and then placed in a holding cage while two identical objects were placed in the left and right corners of the box, $\sim 5 \mathrm{~cm}$ from the walls. Mice were then returned to the box for the sample phase and allowed to freely investigate until they accumulated a total of $30 \mathrm{~s}$ exploring the objects (exploration recorded when the front paws or nose contacted the object). Mice were then removed, immediately injected or infused, and returned to their home cages.

After 24 or $48 \mathrm{~h}$, object recognition was tested in the choice phase, in which a novel object was substituted for one of the familiar sample phase objects. Novel object location was counterbalanced across mice. Time spent with each object was recorded. Mice inherently prefer to explore novel objects; thus, a preference for the novel object [more time than chance (15 s) with the novel object] indicates intact memory for the familiar object. Using $30 \mathrm{~s}$ of total exploration time rather than a fixed trial duration minimizes confounding influences of group differences in activity. Memory retention is delay dependent; mice show memory retention after 24, but not 48, hours (Gresack and Frick, 2004, 2006). Elapsed time to accumulate $30 \mathrm{~s}$ of exploration was recorded to control for group differences in activity levels, but none were observed in any experiment (supplemental Table 1, available at www.jneurosci.org as supplemental material).

Statistical analyses. Separate one-sample $t$ tests were performed for each group to determine whether the time spent with the novel object differed from $15 \mathrm{~s}$. This analysis was used because time spent with the objects is not independent; time spent with one object reduces time spent with the other object (Gresack and Frick, 2003, 2004, 2006). For Western blotting, separate two-tailed unpaired $t$ tests were performed between estradiol-treated groups and their vehicle-treated controls for each ERK isoform. For the Western blotting data shown in Figure $4 b$, a one-way ANOVA was performed including all groups, and Tukey's post hoc comparisons were performed between treatment groups and vehicle controls.

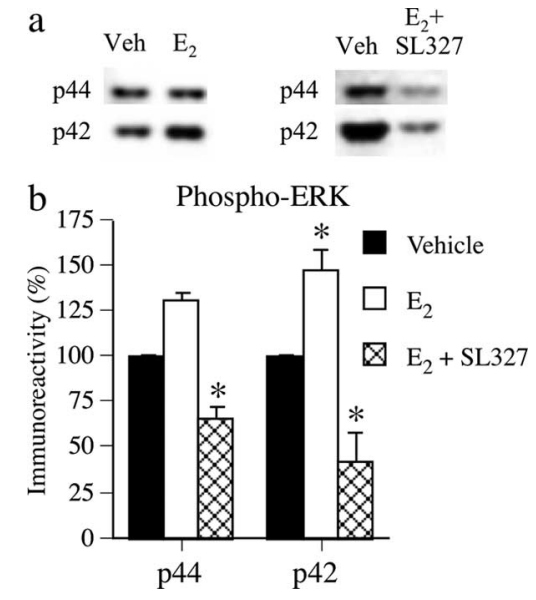

Figure 1. $\quad \boldsymbol{a}$, Representative Western blots showing phosphorylated p42 and p44 ERK protein levels. $\boldsymbol{a}, \boldsymbol{b}, \mathrm{E}_{2}(0.2 \mathrm{mg} / \mathrm{kg}$, i.p.) significantly increased phospho-p42 ERK levels in dorsal hippocampus $1 \mathrm{~h}$ after injection, and $30 \mathrm{mg} / \mathrm{kg} S \mathrm{~S} 327$ completely blocked this increase. Each bar represents mean ( \pm SEM) percentage change from vehicle (Veh) controls $\left({ }^{*} p<0.05\right.$ relative to controls).

The same analyses were performed for the Western blotting data shown in supplemental Figure 4 (available at www.jneurosci.org as supplemental material).

\section{Results}

Estradiol increases ERK activation in dorsal hippocampus

To determine whether acute $\mathrm{E}_{2}$ treatment affected dorsal hippocampal ERK activation, mice were injected intraperitoneally with vehicle, $0.2 \mathrm{mg} / \mathrm{kg} \mathrm{E} \mathrm{E}_{2}(n=6)$, or $30 \mathrm{mg} / \mathrm{kg}$ SL327 plus 0.2

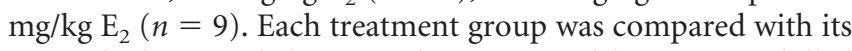
own vehicle controls ( $n=7$ and 8 , respectively). Mice were killed $1 \mathrm{~h}$ later, and the dorsal hippocampus was immediately removed. Western blotting (Fig. 1) of phosphorylated p42 and p44 ERK protein levels showed that $\mathrm{E}_{2}$ significantly increased dorsal hippocampal phospho-p42 ERK levels relative to vehicle controls $\left(t_{(11)}=5.82 ; p<0.001\right)$, and slightly, but not significantly, increased phospho-p44 levels. $\mathrm{E}_{2}$-induced increases in phosphoERK levels were completely blocked by SL327; phospho-p42 and phospho-p44 ERK levels were significantly reduced relative to controls $\left(t_{(15)}=-2.71\right.$ and -3.76 , respectively; $p<0.05$ ) (Fig. $1 b)$.

\section{Estradiol-induced enhancement of object recognition is dependent on dorsal hippocampal ERK activation}

The beneficial effect of $E_{2}$ on object recognition was first demonstrated by injecting mice immediately after the sample phase with vehicle $(n=9)$ or $0.2 \mathrm{mg} / \mathrm{kg} \mathrm{E}_{2}(n=9)$ intraperitoneally and testing retention after 48 h. During the choice phase (Fig. 2a), mice receiving $\mathrm{E}_{2}$ spent significantly more time than chance $(15 \mathrm{~s})$ with the novel object $\left(t_{(8)}=2.63 ; p<0.05\right)$. This preference for the novel object indicates that $E_{2}$ enhanced novel object recognition. Vehicle-treated mice did not prefer either object.

To determine whether the effect of $\mathrm{E}_{2}$ on object recognition was dependent on dorsal hippocampal ERK activation, we infused the MEK inhibitor U0126 bilaterally into dorsal hippocampus immediately after intraperitoneal $0.2 \mathrm{mg} / \mathrm{kg} \mathrm{E}$. To first demonstrate that effects of MEK inhibition on $E_{2}$-induced enhancement of $48 \mathrm{~h}$ object recognition did not result from general prevention of memory formation after the sample phase, we identified doses of U0126 that did not interfere with object recognition at a shorter $24 \mathrm{~h}$ delay. Mice received intrahippocampal 

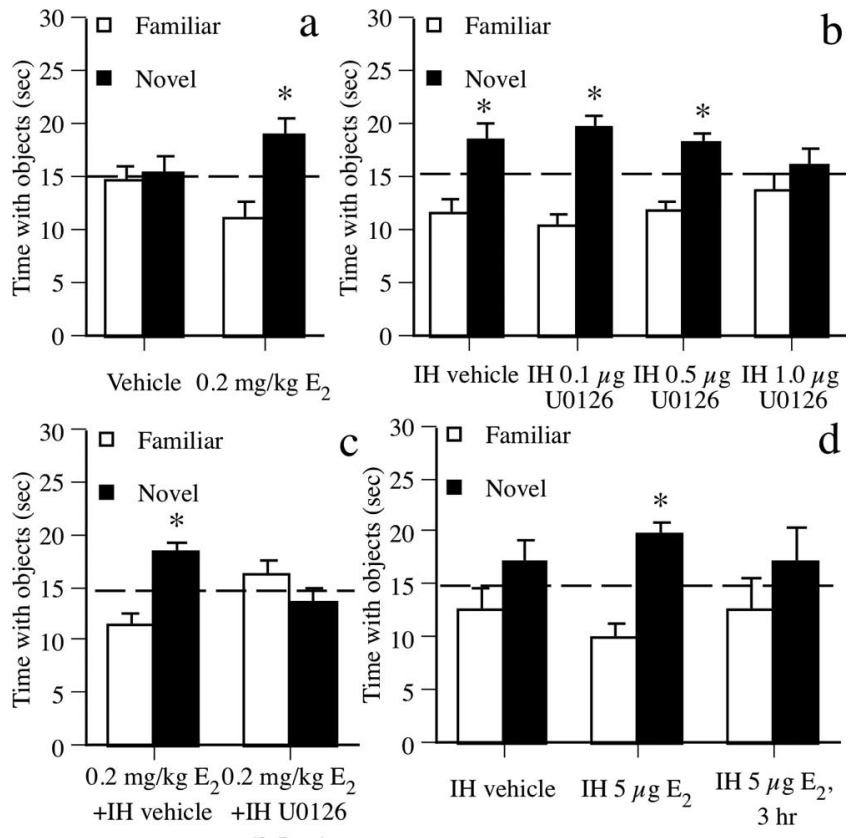

$(0.5 \mu \mathrm{g})$

Figure 2. Object recognition data. $a$, Mice treated with $0.2 \mathrm{mg} / \mathrm{kg} \mathrm{E}_{2}$, but not vehicle, spent significantly more time with the novel object than chance (dashed line at $15 \mathrm{~s}$ ) after $48 \mathrm{~h}$, demonstrating memory for the familiar object. $\boldsymbol{b}$, In mice tested $24 \mathrm{~h}$ posttraining, all but those receiving intrahippocampal (IH) $1.0 \mu \mathrm{g}$ of U0126 spent significantly more time than chance with the novel object, demonstrating that the 0.1 and $0.5 \mu \mathrm{g}$ doses of U0126 did not impair memory at this delay. $c$, Mice receiving $0.2 \mathrm{mg} / \mathrm{kg} \mathrm{E}_{2}$ plus intrahippocampal vehicle exhibited a significant preference for the novel object. This effect was blocked by intrahippocampal $0.5 \mu \mathrm{g}$ of U0126. $\boldsymbol{d}$, Mice receiving intrahippocampal $\mathrm{E}_{2}(5 \mu \mathrm{g})$ spent significantly more time with the novel object than chance, whereas mice receiving intrahippocampal vehicle or intrahippocampal $E_{2}$ after a $3 \mathrm{~h}$ delay did not. Each bar represents the mean ( \pm SEM) time spent with each object $\left({ }^{*} p<0.05\right.$ relative to chance).

vehicle $(n=6), 0.1 \mu \mathrm{g}$ of $\mathrm{U} 0126(n=7), 0.5 \mu \mathrm{g}$ of $\mathrm{U} 0126(n=7)$, or $1.0 \mu \mathrm{g}$ of U0126 $(n=6)$ immediately after the sample phase. Twenty-four hours later (Fig. $2 b$ ), mice receiving intrahippocampal vehicle, $0.1 \mu \mathrm{g}$ of U0126, and $0.5 \mu \mathrm{g}$ of U0126 exhibited a significant preference for the novel object (values of $t_{(5-6)}=2.5$ 4.4; $p<0.05$ ), whereas mice receiving $1.0 \mu \mathrm{g}$ of U0126 did not, indicating that 0.1 and $0.5 \mu \mathrm{g}$ of U0126 did not generally prevent memory formation in this task. We then paired $0.2 \mathrm{mg} / \mathrm{kg} \mathrm{E}_{2}$ injections with intrahippocampal infusion of vehicle $(n=7)$ or the highest ineffective U0126 dose $(0.5 \mu \mathrm{g} /$ side; $n=7)$ immediately after the sample phase, and tested memory retention after $48 \mathrm{~h}$. Mice receiving $\mathrm{E}_{2}$ plus intrahippocampal vehicle exhibited a significant preference for the novel object $\left(t_{(9)}=3.83 ; p<0.05\right.$ ) (Fig. $2 c$ ), whereas the $\mathrm{E}_{2}$ plus intrahippocampal U0126 group did not, demonstrating that $\mathrm{E}_{2}$-induced facilitation of object recognition is dependent on dorsal hippocampal ERK activation.

\section{Intrahippocampal infusion of estradiol enhances object recognition}

To further emphasize the role of the hippocampus in mediating effects of $\mathrm{E}_{2}$ object memory, we next asked whether intrahippocampal $\mathrm{E}_{2}$ infusion could enhance object recognition. Immediately after the sample phase, mice received bilateral intrahippocampal infusions of vehicle $(n=10)$ or $5.0 \mu \mathrm{g} /$ side $\mathrm{E}_{2}(n=9)$ (Packard and Teather, 1997a). Forty-eight hours later (Fig. 2d), mice receiving intrahippocampal $\mathrm{E}_{2}$ exhibited a significant preference for the novel object $\left(t_{(8)}=4.52 ; p<0.01\right)$, whereas vehicle controls did not, suggesting that the dorsal hippocampus can
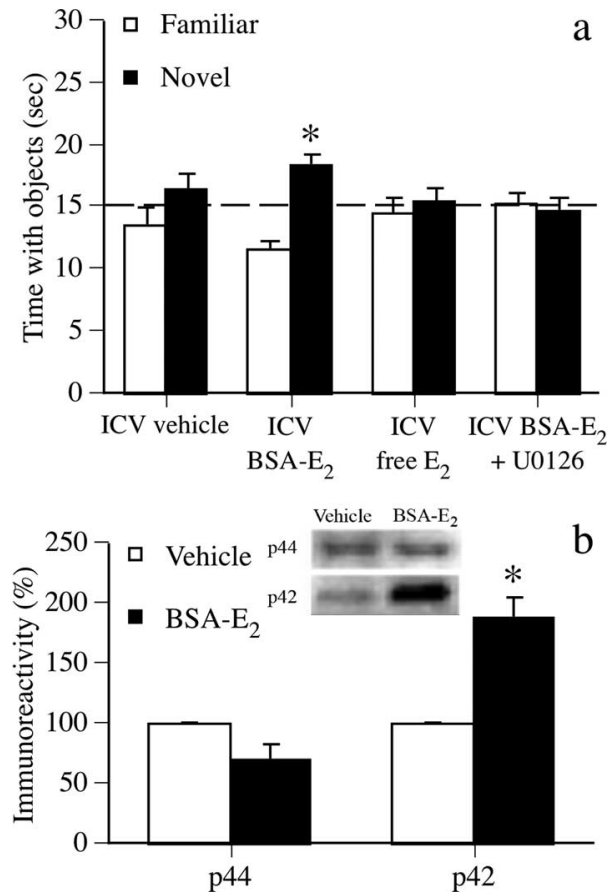

Figure 3. $\boldsymbol{a}$, Mice receiving intracerebroventricular (ICV) BSA-E, spent significantly more time with the novel object than chance (dashed line at $15 \mathrm{~s}$ ), thus demonstrating memory for the familiar object. This effect was blocked by intrahippocampal $0.5 \mu \mathrm{g}$ U0126. Controls receiving intracerebroventricular vehicle or intracerebroventricular $850 \mathrm{pg} / \mu \mathrm{l}$ free $\mathrm{E}_{2}$ also did not prefer the novel object. Each bar represents the mean ( \pm SEM) time spent with each object $\left({ }^{*} p<0.05\right.$ relative to chance). $\boldsymbol{b}$, Intracerebroventricular $B S A-E_{2}$ significantly increased phospho-p42, but not phospho-p44, ERK levels in the dorsal hippocampus 5 min after infusion. Each bar represents mean ( \pm SEM) percentage change from vehicle controls $\left({ }^{*} p<0.05\right.$ relative to controls). Inset, Representative Western blots showing phosphorylated p42 and p44 ERK protein levels.

mediate effects of $\mathrm{E}_{2}$ on object recognition. To demonstrate that this effect occurs within hours of infusion, mice received intrahippocampal infusions of $5.0 \mu \mathrm{g} /$ side $\mathrm{E}_{2}(n=5) 3 \mathrm{~h}$ after the sample phase. These mice did not exhibit a preference for the novel object after $48 \mathrm{~h}$ (Fig. $2 d$ ), indicating that beneficial effects of $\mathrm{E}_{2}$ occur within $3 \mathrm{~h}$ of injection.

\section{Estradiol binding to membrane-bound ERs can enhance} object recognition and hippocampal ERK activation

To determine whether membrane-bound ERs can mediate $\mathrm{E}_{2}$ induced alterations of object recognition, we next asked whether the effects of $E_{2}$ on object recognition and dorsal hippocampal ERK activation could be duplicated by membrane-impermeable BSA- $E_{2}$. Immediately after the sample phase, mice received an intracerebroventricular infusion of vehicle $(n=9)$ or $5.0 \mu \mathrm{M}$ BSA- $_{2}(n=10)$ (Kuroki et al., 2000). As a control for effects of trace amounts of $\mathrm{E}_{2}$ that may have come unbound from the BSA molecule, another group was infused with $850 \mathrm{pg} / \mu \mathrm{l} 17 \beta$ estradiol $(n=10)$, the amount of free $\mathrm{E}_{2}$ calculated in our preparation based on previous work (Stevis et al., 1999). BSA-E $\mathrm{E}_{2}$ mice exhibited a significant preference for the novel object after $48 \mathrm{~h}$ (Fig. $3 a)\left(t_{(9)}=4.88 ; p<0.01\right)$, whereas vehicle and free $\mathrm{E}_{2}$ groups did not. Other mice $(n=9)$ received intracerebroventricular infusion of $5.0 \mu \mathrm{M}$ BSA-E $\mathrm{E}_{2}$ plus intrahippocampal infusion of U0126 (0.5 $\mu \mathrm{g} /$ side $)$ immediately after the sample phase; this group did not spend significantly more time than chance with the novel object (Fig. $3 a$ ). Together, these data suggest that activation of membrane-bound ERs by BSA-E $\mathrm{E}_{2}$ can enhance object recog- 
nition and that this effect is dependent on dorsal hippocampal ERK activation. To demonstrate that $\mathrm{BSA}-\mathrm{E}_{2}$ can increase dorsal hippocampal ERK activation, other mice received intracerebroventricular infusion of vehicle $(n=3)$ or $5.0 \mu \mathrm{M} \mathrm{BSA}-\mathrm{E}_{2}(n=5)$ and were killed 5 min later. BSA- $\mathrm{E}_{2}$ significantly increased dorsal hippocampal phospho-p42 ERK levels 5 min after infusion $\left(t_{(6)}\right.$ $=-6.51 ; p<0.001)$, but did not affect phospho-p44 ERK levels (Fig. $3 b)$.

\section{Effects of BSA-E $\mathrm{E}_{2}$ on object recognition are independent of nuclear ERs}

Although mice infused intracerebroventricularly with free $E_{2}$ did not show a significant preference for the novel object, it remains possible that this control does not adequately account for the dissociation of $\mathrm{E}_{2}$ from the BSA molecule within the hippocampus. Thus, to ensure that the beneficial effects of BSA-E $\mathrm{E}_{2}$ on object memory consolidation and phospho-p42 ERK activation were not attributable to free $\mathrm{E}_{2}$ binding to nuclear ERs, a new set of mice received infusions of vehicle (both intrahippocampal and intracerebroventricular; $n=9$ ) or intracerebroventricular infusion of BSA-E $\mathrm{E}_{2}$ concurrently with intrahippocampal infusion of the nuclear ER antagonist ICI $182,780(n=9)$ immediately after the sample phase. Forty-eight hours later, mice receiving intracerebroventricular BSA-E 2 plus intrahippocampal ICI 182,780, but not those receiving vehicle, spent significantly more time with the novel object than chance $\left(t_{(8)}=2.99 ; p<0.05\right)$ (Fig. $\left.4 a\right)$, suggesting that an $\mathrm{ER} \alpha / \beta$ antagonist does not prevent $\mathrm{BSA}-\mathrm{E}_{2}$ from enhancing object memory consolidation. Effects on ERK activation in the CA1 subregion of the dorsal hippocampus were measured in other mice using separate one-way ANOVAs for each ERK isoform conducted on all groups shown in Figure $4 b$. The main effect of treatment was significant for phospho-p42 ERK levels $\left(F_{(7,30)}=2.77 ; p<0.05\right)$ (Fig. $\left.4 b\right)$, and thus, effects of Tukey's post hoc tests performed subsequent to this ANOVA will be described in the paragraphs below. In contrast to phopho-p42 ERK, the main effect of treatment was not significant for phospho-p44 ERK levels (supplemental Fig. 4, available at www.jneurosci.org as supplemental material); as such, the paragraphs below describe effects on phospho-p42 ERK levels only. For mice receiving intracerebroventricular BSA- $\mathrm{E}_{2}$ plus intrahippocampal ICI 182,780 $(n=5)$, Tukey's post hoc tests revealed that dorsal CA1 levels of phospho-p42 ERK 5 min after infusion were not significantly different from either vehicle controls $(n=4)$ or mice receiving intracerebroventricular BSA-E $\mathrm{E}_{2}$ plus intrahippocampal vehicle $(n=5)$ (Fig. $4 b)$. This intermediate effect on phopho-p42 ERK suggests that ICI 182,780 only partially blocked the beneficial effects of intracerebroventricular BSA- $\mathrm{E}_{2}$. The residual phosphop42 ERK activation still present after ICI 182,780 administration may have been sufficient to produce enhanced memory consolidation, because this group demonstrated a significant preference for the novel object.

To address the possibility that ICI 182,780 acts as an agonist in the absence of BSA-E $E_{2}$ or $\mathrm{E}_{2}$ (Zhao et al., 2005; Zurkovsky et al., 2006), we then infused ICI 182,780 intrahippocampally (without concurrent intracerebroventricular infusion) immediately after training and found that this treatment had no significant effect on object memory consolidation tested 48 h later $(n=9)$ (Fig. $4 a)$ or on dorsal CA1 levels of phospho-p42 ERK measured 5 min after infusion $(n=4)$ (Fig. $4 b$ ). This finding suggests that ICI 182,780 does not act as an agonist in the context of this experimental design and that the beneficial effect of intracerebroventricular $\mathrm{BSA}_{2} \mathrm{E}_{2}$ plus intrahippocampal ICI 182,780 on object recognition was not attributable to memory- or ERK-enhancing effects of ICI
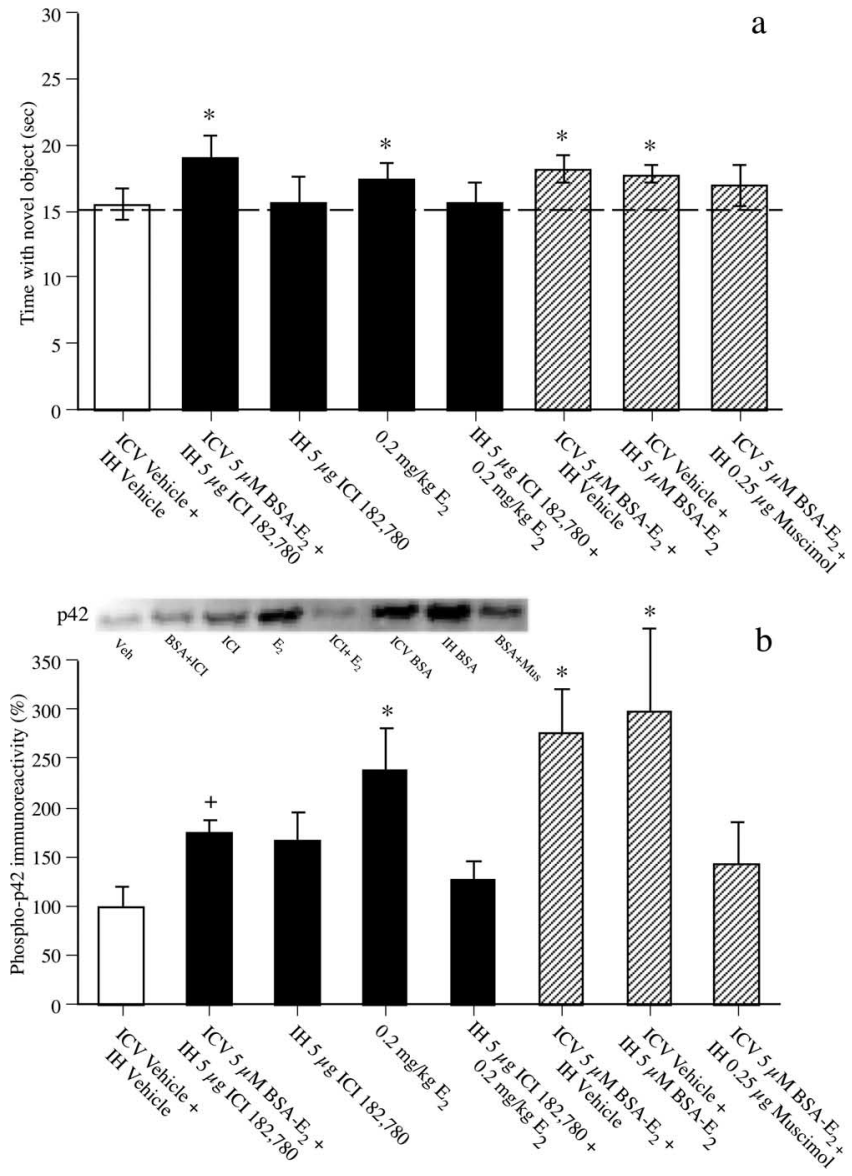

Figure 4. $\quad \boldsymbol{a}$, Time spent with the novel object $48 \mathrm{~h}$ after intracerebroventricular (ICV), intrahippocampal (IH), or intraperitoneal drug administration (bars for the familiar object are omitted for simplicity). Mice treated with intracerebroventricular $5 \mu \mathrm{MBSA}-\mathrm{E}_{2}$ plus intrahippocampal $5 \mu \mathrm{g}$ of ICl 182,780, $0.2 \mathrm{mg} / \mathrm{kg} \mathrm{E}_{2}$ (intraperitoneal), intracerebroventricular $5 \mu \mathrm{M} \mathrm{BSA-E_{2 }}$ plus intrahippocampal vehicle, and intracerebroventricular vehicle plus intrahippocampal $5 \mu \mathrm{M}$ $B S A-E_{2}$ spent significantly more time with the novel object than chance (dashed line at $15 \mathrm{~s}$ ) after $48 \mathrm{~h}$, demonstrating memory for the familiar object. All other groups failed to exhibit a significant preference for the novel object relative to chance. In brief, these data show that 0.2 $\mathrm{mg} / \mathrm{kg} \mathrm{E}_{2}$ and $B S A-E_{2}$ administered into either the dorsal third ventricle or dorsal hippocampus enhance object recognition, and that ICI 182,780 can block the effects of $E_{2}$, but not of $B S A-E_{2}$, on object recognition. The data also show that $I C \mid 182,780$ does not act as an agonist in this task, and that dorsal hippocampal inactivation with muscimol reduces the beneficial effects of $B S A-E_{2}$ on object memory. Each bar represents the mean ( \pm SEM) time spent with each object $\left({ }^{*} p<0.05\right.$ relative to chance). $\boldsymbol{b}$, Phospho-p42 ERK levels in dorsal CA1 were measured $5 \mathrm{~min}$ after infusion in all groups but those receiving $0.2 \mathrm{mg} / \mathrm{kg} \mathrm{E}_{2}$, in which mice were killed $60 \mathrm{~min}$ after $E_{2}$ injection (5 min after ICI 182,780 infusion in the $E_{2}$ plus ICI 182,780 group). Phosphop42 ERK levels in dorsal CA1 were significantly increased relative to intracerebroventricular vehicle plus intrahippocampal vehicle controls in groups receiving $0.2 \mathrm{mg} / \mathrm{kg} \mathrm{E}_{2}$, intracerebroventricular $B S A-E_{2}$ plus intrahippocampal vehicle, and intracerebroventricular vehicle plus intrahippocampal $B S A-E_{2}{ }^{*} p<0.05$ relative to vehicle controls). Thus, administration of $E_{2}$ or $B S A-E_{2}$ alone significantly increased phospho-p42 ERK levels in dorsal CA1. Phospho-p42 ERK levels in other groups did not differ significantly from controls. Of note, levels in the intracerebroventricular BSA-E $E_{2}$ plus intrahippocampal ICI 182,780 group were not significantly different from vehicle controls or from the group receiving intracerebroventricular $B S A-E_{2}$ plus intrahippocampal vehicle ( ${ }^{+} p<0.05$ relative to both groups), suggesting a partial blockade of the effects of $B S A-E_{2}$ by ICI 182,780. Each bar represents mean ( \pm SEM) percentage change from intracerebroventricular vehicle plus intrahippocampal vehicle controls. Inset, Representative Western blots showing phosphorylated p42 ERK protein levels (note that the order of the bands matches the order of the bars in the figure; group names are abbreviated for simplicity).

182,780 . To ensure that the dose of ICI 182,780 used in combination with BSA- $\mathrm{E}_{2}$ was sufficient to block the effects of traditional $\mathrm{E}_{2}$, ICI 182,780 was infused intrahippocampally 55 min after an intraperitoneal injection of $0.2 \mathrm{mg} / \mathrm{kg} \mathrm{E}_{2}$. ICI 182,780 
completely blocked the beneficial effect of systemic $\mathrm{E}_{2}$ on novel object recognition $(n=9)$, such that exploration of the novel object in the $\mathrm{E}_{2}$ plus intrahippocampal ICI 182,780 group was not significantly greater than chance (Fig. $4 a)\left(0.2 \mathrm{mg} / \mathrm{kg} \mathrm{E} \mathrm{E}_{2}\right.$ data reprinted from Fig. $2 a$ ). For analysis of dorsal CA1 ERK activity, a separate set of mice was killed $60 \mathrm{~min}$ after injection of $\mathrm{E}_{2}$, either alone or in combination with ICI 182,780 (which was infused intrahippocampally $5 \mathrm{~min}$ before mice were killed). Tukey's post hoc tests revealed that $0.2 \mathrm{mg} / \mathrm{kg} \mathrm{E}_{2}$ significantly increased dorsal CA1 phopho-p42 ERK activation, whereas ICI 182,780 blocked this effect $\left(\mathrm{E}_{2}, n=5 ; \mathrm{E}_{2}\right.$ plus ICI 182,780, $\left.n=5\right)$ (Fig. $\left.4 b\right)$. These data suggest that the dose of ICI 182,780 used in this study was sufficient to block both the behavioral and biochemical effects of traditional $\mathrm{E}_{2}$, but not of BSA-E $\mathrm{E}_{2}$. Together with the BSA-E $\mathrm{E}_{2}$ data, these findings indicate that membrane-associated ERs can mediate the effects of $E_{2}$ on object memory consolidation and dorsal hippocampal ERK activation, but suggest that nuclear ERs may also be involved in these effects, possibly via a nongenomic mechanism.

\section{The dorsal hippocampus is a critical locus for the effects of BSA-E}

To determine whether the dorsal hippocampus is critical to the effects on BSA-E $E_{2}$ on object memory and ERK activation, we next asked whether BSA- $\mathrm{E}_{2}$ infused directly into the dorsal hippocampus could enhance object memory and increase dorsal CA1 ERK activation similar to intracerebroventricular $\mathrm{BSA}-\mathrm{E}_{2}$ infusion. Immediately after the sample phase, mice received $B S A-E_{2}$ infused either intracerebroventricularly $(n=10)$ or intrahippocampally $(n=10)$ plus vehicle infused to the alternate site (so that all mice received infusions in both sites). Forty-eight hours later, mice infused with BSA- $\mathrm{E}_{2}$ into either the dorsal third ventricle $\left(t_{(9)}=3.16 ; p<0.05\right)$ or dorsal hippocampus $\left(t_{(9)}=4.21\right.$; $p<0.05)$ spent significantly more time than chance with the novel object, whereas vehicle controls did not (Fig. 4a). Tukey's post hoc tests conducted subsequent to the phospho-p42 ERK ANOVA described above revealed that both BSA- $\mathrm{E}_{2}$ treatments ( $n=5$ for intracerebroventricular BSA- $\mathrm{E}_{2}$ and $n=5$ for intrahippocampal BSA-E ${ }_{2}$ ) significantly increased dorsal CA1 phospho-p42 ERK levels $5 \mathrm{~min}$ after infusion relative to vehicle controls ( $n=4 ; p<0.05$ for both comparisons) (Fig. $4 b)$. These data not only replicate the intracerebroventricular BSA- $\mathrm{E}_{2}$ data described in Figure 3, but also suggest that the effects of BSA-E on object memory consolidation can be mediated by the dorsal hippocampus.

Although these data suggest a role for the dorsal hippocampus in BSA- $\mathrm{E}_{2}$-induced enhancement of object memory consolidation, they do not address whether the dorsal hippocampus is critical for BSA- $\mathrm{E}_{2}$-induced memory enhancement. Therefore, other mice were infused concurrently with $B S A-E_{2}$ intracerebroventricularly and muscimol intrahippocampally. To ensure that the dose of muscimol used did not block general memory formation in the task regardless of BSA- $\mathrm{E}_{2}$ treatment, a different set of mice was given posttraining intrahippocampal infusions of vehicle $(n=8)$ or one of three doses of muscimol $(0.1 \mu \mathrm{g} / \mathrm{side}$, $n=8 ; 0.25 \mu \mathrm{g} /$ side, $n=8 ; 0.5 \mu \mathrm{g} /$ side, $n=8)$ and tested $24 \mathrm{~h}$ later. Mice receiving vehicle $\left(t_{(7)}=3.17 ; p<0.05\right), 0.1 \mu \mathrm{g} /$ side $\left(t_{(7)}=3.63 ; p<0.05\right)$, or $0.25 \mu \mathrm{g} /$ side $\left(t_{(7)}=6.40 ; p<0.05\right)$ muscimol spent significantly more time with the novel object than chance, whereas mice receiving $0.5 \mu \mathrm{g} /$ side muscimol did not (supplemental Fig. $3 a$, available at www.jneurosci.org as supplemental material). These data demonstrate that intrahippocampal infusion of a high dose of muscimol can significantly impair object recognition memory, thereby illustrating a important role of the dorsal hippocampus in mediating object memory consolidation in this task, and establish two subeffective doses for use with BSA-E $\mathrm{E}_{2}$ that do not disrupt object memory when administered alone. Next, the higher of the subeffective muscimol doses $(0.25 \mu \mathrm{g} / \mathrm{side})$ was then infused intrahippocampally concurrently with intracerebroventricular BSA- $\mathrm{E}_{2}(n=11)$ immediately after the sample phase. Forty-eight hours later, these mice showed no significant preference for the novel object (Fig. 4a), suggesting that temporary inactivation of the dorsal hippocampus interferes with the effects of intracerebroventricular BSA-E administration and indicating a critical role for the dorsal hippocampus in BSA- $\mathrm{E}_{2}$-induced enhancement of object memory consolidation. Similar to its effects on memory, muscimol also blocked the BSA- $\mathrm{E}_{2}$-induced increase in dorsal CA1 phosphop42 ERK levels 5 min after infusion $(n=4)$, such that no significant difference in phospho-p42 ERK levels was observed between mice infused with vehicle or with intracerebroventricular BSA- $\mathrm{E}_{2}$ plus intrahippocampal muscimol (Fig. 4b). Together, these data indicate that reversible inactivation of the dorsal hippocampus interferes with $\mathrm{BSA}-\mathrm{E}_{2}$-induced increases in object recognition and dorsal CA1 phospho-p42 ERK activation, and highlight the importance of dorsal hippocampal activity to the effects of BSA-E $\mathrm{E}_{2}$.

\section{Discussion}

The $\mathrm{E}_{2}$-induced increase in dorsal hippocampal phospho-p42 ERK levels is supported by previous studies demonstrating that $\mathrm{E}_{2}$ can increase hippocampal ERK activation in vitro and in vivo. For example, in cultured rodent hippocampal neurons, $\mathrm{E}_{2}$ rapidly increased phospho-p42 and phospho-p44 ERK levels (Nilsen and Brinton, 2003; Yokomaku et al., 2003), effects that were blocked by U0126 (Yokomaku et al., 2003). In male rats, an intracerebroventricular infusion of $\mathrm{E}_{2}$ rapidly increased ERK activation (no particular isoform specified) in hippocampal CA1 and dentate gyrus within 5 min of administration (Kuroki et al., 2000). Our laboratory also recently showed that $0.2 \mathrm{mg} / \mathrm{kg} \mathrm{E}_{2}$ significantly increased phospho-p42 ERK levels in the dorsal hippocampus $60 \mathrm{~min}$ after injection and that this effect was associated with enhanced object recognition (Lewis et al., 2008). The beneficial effects of $E_{2}$ on object memory and dorsal hippocampal phospho-p42 ERK levels were linked with several signaling pathways upstream from ERK, because the effects of $E_{2}$ on both memory and ERK activation were reduced, but not completely blocked, by bilateral infusion into the dorsal hippocampus of the NMDA receptor antagonist, AP5, and the protein kinase A (PKA) inhibitor, Rp-cAMPS (Lewis et al., 2008). Thus, these data suggest that $\mathrm{E}_{2}$-induced enhancements of object memory consolidation and dorsal hippocampal ERK activation involve the NMDA and PKA pathways. Although both pathways can activate ERK (Sweatt, 2004), the fact that neither treatment completely blocked the effects of $E_{2}$ on ERK activation may suggest that other signaling pathways upstream from ERK, such as those initiated by receptor tyrosine kinases or phospholipase C-coupled receptors (Sweatt, 2004), also contribute to estrogenic modulation of ERK activation.

The present data demonstrating that posttraining intraperitoneal $\mathrm{E}_{2}$ injection enhanced object memory consolidation are consistent with other reports that intraperitoneal $\mathrm{E}_{2}$ (including the $0.2 \mathrm{mg} / \mathrm{kg}$ dose) administered immediately posttraining enhanced object recognition and spatial memory (Packard et al., 1996; Packard and Teather, 1997b; Gresack and Frick, 2006). Our present finding that intrahippocampal $\mathrm{E}_{2}$ infusion enhanced ob- 
ject memory consolidation is also consistent with a previous report in ovariectomized female rats that posttraining dorsal hippocampal $\mathrm{E}_{2}$ infusion enhances spatial memory consolidation (Packard et al., 1996). Additionally, our data demonstrate that $\mathrm{E}_{2}$ enhances object memory consolidation within $3 \mathrm{~h}$ after training, and our finding that systemic $\mathrm{E}_{2}$ increased dorsal hippocampal ERK activation $60 \mathrm{~min}$ after injection fits well within this time frame. As such, $\mathrm{E}_{2}$-induced increases in hippocampal ERK activity within $60 \mathrm{~min}$ of administration may be responsible for rapid $\mathrm{E}_{2}$-induced improvements in memory consolidation in tasks involving the hippocampus, such as object recognition (Clark et al., 2000; Baker and Kim, 2002).

The fact that the beneficial effect of $\mathrm{E}_{2}$ on memory consolidation was blocked by MEK inhibition is consistent with other reports demonstrating that posttraining manipulation of ERK signaling prevents long-term memory consolidation in hippocampal-dependent tasks. For example, posttraining infusion of the MEK inhibitor 2-(2-amino-3-methyoxyphenyl)-4 H1-benzopyran-4-one (PD098059) into dorsal hippocampus disrupted spatial memory consolidation in the Morris water maze (Blum et al., 1999), and posttraining infusion of U0126 or PD098059 into dorsal hippocampal CA1 impaired long-term memory for inhibitory avoidance (Walz et al., 2000; Zhang et al., 2004). The current finding that $\mathrm{E}_{2}$-induced facilitation of object memory consolidation is dependent on ERK activation, along with the fact that $\mathrm{E}_{2}$ only increased levels of activated p42 (but not p44) ERK, may suggest that p42 is critical in mediating effects of $\mathrm{E}_{2}$ on memory. This notion is consistent with evidence implicating p42 as the more important isoform in learning and memory processes; deletion of p44 in mice has no effect on memory (Selcher et al., 2001) or facilitates memory retention in certain tasks (Mazzucchelli et al., 2002).

The estrogen receptor mechanisms by which $\mathrm{E}_{2}$ increases $\mathrm{ERK}$ activation, and thus enhances memory, are not yet clear. Several studies suggest involvement of nuclear ERs in $\mathrm{E}_{2}$-induced ERK activation in the hippocampus. For example, treatment with ICI 182,780 inhibited $\mathrm{E}_{2}$-induced ERK activation in cultured mouse hippocampal neurons (Yokomaku et al., 2003), and nuclear ERspecific effects on $\mathrm{E}_{2}$-induced ERK activity have also been reported (Singh et al., 2000; Wade et al., 2001; Abrahám et al., 2004), implicating involvement of these receptors. Furthermore, the fact that ICI 182,780 in the present study blocked the effects of $\mathrm{E}_{2}$ on object recognition and dorsal CA1 phopho-p42 ERK levels indicates that nuclear ERs act in a nongenomic manner to facilitate rapid effects on signal transduction and memory. This possibility is supported by the extranuclear localization of $\operatorname{ER} \alpha$ and ER $\beta$ to sites throughout hippocampal pyramidal neurons, including dendritic spines, axons, and axon terminals (Milner et al., $2001,2005)$. Furthermore, one recent study demonstrates that $E_{2}$ causes $\mathrm{ER} \beta$, but not $\mathrm{ER} \alpha$, to translocate to the plasma membrane in primary cortical cultures, in which it can then activate ERK/ MAPK signaling (Sheldahl et al., 2008). The functional role of nongenomic actions of ERs will need to be further elucidated in future studies.

The present and previous (Kuroki et al., 2000) findings also demonstrate that intracerebroventricular or intrahippocampal infusions of BSA-E $\mathrm{E}_{2}$ also elevate ERK activation in the dorsal hippocampus and that these effects can occur in the presence of a nuclear ER antagonist. The role of membrane-bound ERs in mediating memory consolidation specifically has never before been investigated. Thus, our finding that $\mathrm{BSA}-\mathrm{E}_{2}$ facilitated object memory consolidation is the first to suggest a clear role for membrane-bound ERs in $\mathrm{E}_{2}$-induced memory alterations. The involvement of membrane-bound ERs in memory consolidation was further supported by the present finding that the nuclear ER antagonist ICI 182,780 did not block the beneficial effect of $\mathrm{BSA}-\mathrm{E}_{2}$ on object recognition. If BSA- $\mathrm{E}_{2}$ influenced object recognition or dorsal hippocampal ERK activation primarily via nuclear ERs (e.g., by the liberation of free $\mathrm{E}_{2}$ ), then ICI 182,780 should have blocked the BSA- $\mathrm{E}_{2}$-induced enhancements of both memory and ERK in a manner similar to $\mathrm{E}_{2}$. The fact that neither object recognition nor dorsal CA1 ERK activation were completely blocked by ICI 182,780 suggests that membrane-bound ERs alone can mediate the rapid effects of $E_{2}$ on object memory consolidation via nontraditional mechanisms such as ERK activation.

In summary, the present study indicates that $\mathrm{E}_{2}$-induced enhancement of object memory consolidation is dependent on dorsal hippocampal ERK activation and can be mediated by membrane-associated ERs. Given that membrane-bound receptors are not yet fully characterized (Norfleet et al., 1999; Razandi et al., 1999; Watson et al., 1999a,b; Toran-Allerand et al., 2002), this is a particularly novel finding. The present data also support a key role for the dorsal hippocampus in the BSA-E $\mathrm{E}_{2}$ effect, as indicated by the enhancement of object recognition and phospho-p42 ERK levels after dorsal hippocampal infusions of BSA- $\mathrm{E}_{2}$ and the disruption of the effects of intracerebroventricular BSA- $\mathrm{E}_{2}$ by intrahippocampal muscimol. The data, therefore, demonstrate the involvement of a specific molecular pathway in the dorsal hippocampus, as well as a novel ER mechanism, underlying the effects of $\mathrm{E}_{2}$ on object memory consolidation.

\section{References}

Abrahám IM, Todman MG, Korach KS, Herbison AE (2004) Critical in vivo roles for classical estrogen receptors in rapid estrogen actions on intracellular signaling in mouse brain. Endocrinology 145:3055-3061.

Atkins CM, Selcher JC, Petraitis JJ, Trzaskos JM, Sweatt JD (1998) The MAPK cascade is required for mammalian associative learning. Nat Neurosci 1:602-609.

Baker KB, Kim JJ (2002) Effects of stress and hippocampal NMDA receptor antagonism on recognition memory in rats. Learn Mem 9:58-65.

Blum S, Moore AN, Adams F, Dash PK (1999) A mitogen-activated protein kinase cascade in the CA1/CA2 subfield of the dorsal hippocampus is essential for long-term spatial memory. J Neurosci 19:3535-3544.

Bozon B, Kelly A, Josselyn SA, Silva AJ, Davis S, Laroche S (2003) MAPK, CREB and zif268 are all required for the consolidation of recognition memory. Philos Trans R Soc Lond B Biol Sci 358:805-814.

Clark RE, Zola SM, Squire LR (2000) Impaired recognition memory in rats after damage to the hippocampus. J Neurosci 20:8853-8860.

Dauvois S, White R, Parker MG (1993) The antiestrogen ICI 182780 disrupts estrogen receptor nucleocytoplasmic shuttling. J Cell Sci 106:1377-1388

Fernandez SM, Frick KM (2004) Chronic oral estrogen affects memory and neurochemistry in middle-aged female mice. Behav Neurosci 118:1340-1351.

Gresack JE, Frick KM (2003) Male mice exhibit better spatial working and reference memory than females in a water-escape radial arm maze task. Brain Res 982:98-107

Gresack JE, Frick KM (2004) Environmental enrichment reduces the mnemonic and neural benefits of estrogen. Neuroscience 128:459-471.

Gresack JE, Frick KM (2006) Post-training estrogen enhances spatial and object memory consolidation in female mice. Pharmacol Biochem Behav 84:112-119.

Kelly A, Laroche S, Davis S (2003) Activation of mitogen-activated protein kinase/extracellular signal-regulated kinase in hippocampal circuitry is required for consolidation and reconsolidation of recognition memory. J Neurosci 23:5354-5360.

Kuroki Y, Fukushima K, Kanda Y, Mizuno K, Watanabe Y (2000) Putative membrane-bound estrogen receptors possibly stimulate mitogenactivated protein kinase in the rat hippocampus. Eur J Pharmacol 400:205-209. 
Lewis MC, Kerr KM, Orr PT, Frick KM (2008) Estradiol-induced enhancement of object memory consolidation involves NMDA receptors and protein kinase $\mathrm{A}$ in the dorsal hippocampus of female C57BL/6 mice. Behav Neurosci 122:716-721.

Luine VN, Jacome LF, Maclusky NJ (2003) Rapid enhancement of visual and place memory by estrogens in rats. Endocrinology 144:2836-2844.

Martin JH (1991) Autoradiographic estimation of the extent of reversible inactivation produced by microinjection of lidocaine and muscimol in the rat. Neurosci Lett 127:160-164.

Mazzucchelli C, Vantaggiato C, Ciamei A, Fasano S, Pakhotin P, Krezel W, Welzl H, Wolfer DP, Pagès G, Valverde O, Marowsky A, Porrazzo A, Orban PC, Maldonado R, Ehrengruber MU, Cestari V, Lipp HP, Chapman PF, Pouysségur J, Brambilla R (2002) Knockout of ERK1 MAP kinase enhances synaptic plasticity in the striatum and facilitates striatalmediated learning and memory. Neuron 34:807-820.

Milner TA, McEwen BS, Hayashi S, Li CJ, Reagan LP, Alves SE (2001) Ultrastructural evidence that hippocampal alpha estrogen receptors are located at extranuclear sites. J Comp Neurol 429:355-371.

Milner TA, Ayoola K, Drake CT, Herrick SP, Tabori NE, McEwen BS, Warrier S, Alves SE (2005) Ultrastructural localization of estrogen receptor beta immunoreactivity in the rat hippocampal formation. J Comp Neurol 491:81-95.

Nilsen J, Brinton RD (2003) Divergent impact of progesterone and medroxyprogesterone acetate (Provera) on nuclear mitogen-activated protein kinase signaling. Proc Natl Acad Sci U S A 100:10506-10511.

Norfleet AM, Thomas ML, Gametchu B, Watson CS (1999) Estrogen receptor-alpha detected on the plasma membrane of aldehyde-fixed GH3/B6/F10 rat pituitary tumor cells by enzyme-linked immunocytochemistry. Endocrinology 140:3805-3814.

Packard MG, Teather LA (1997a) Intra-hippocampal estradiol infusion enhances memory in ovariectomized rats. Neuroreport 8:3009-3013.

Packard MG, Teather LA (1997b) Posttraining estradiol injections enhance memory in ovariectomized rats: cholinergic blockade and synergism. Neurobiol Learn Mem 68:172-188.

Packard MG, Kohlmaier JR, Alexander GM (1996) Posttraining intrahippocampal estradiol injections enhance spatial memory in male rats: interaction with cholinergic systems. Behav Neurosci 110:626-632.

Paxinos G, Franklin, KBJ (2001) The mouse brain in stereotaxic coordinates, Ed 2. San Diego: Academic.

Razandi M, Pedram A, Greene GL, Levin ER (1999) Cell membrane and nuclear estrogen receptors (ERs) originate from a single transcript: studies of ERalpha and ERbeta expressed in Chinese hamster ovary cells. Mol Endocrinol 13:307-319.

Runyan JD, Moore AN, Dash PK (2004) A role for prefrontal cortex in memory storage for trace fear conditioning. J Neurosci 24:1288-1295.

Schafe GE, Atkins CM, Swank MW, Bauer EP, Sweatt JD, LeDoux JE (2000) Activation of ERK/MAP kinase in the amygdala is required for memory consolidation of pavlovian fear conditioning. J Neurosci 20:8177-8187.

Selcher JC, Nekrasova T, Paylor R, Landreth GE, Sweatt JD (2001) Mice lacking the ERK1 isoform of MAP kinase are unimpaired in emotional learning. Learn Mem 8:11-19.

Sheldahl LC, Shapiro RA, Bryant DN, Koerner IP, Dorsa DM (2008) Estrogen induces rapid translocation of estrogen receptor beta, but not estrogen receptor alpha, to the neuronal plasma membrane. Neuroscience 153:751-761.

Singh M, Sétáló G Jr, Guan X, Frail DE, Toran-Allerand CD (2000)
Estrogen-induced activation of the mitogen-activated protein kinase cascade in the cerebral cortex of estrogen receptor- $\alpha$ knock-out mice. J Neurosci 20:1694-1700.

Stevis PE, Deecher DC, Suhadolnik L, Mallis LM, Frail DE (1999) Differential effects of estradiol and estradiol-BSA conjugates. Endocrinology 140:5455-5458.

Sweatt JD (2004) Mitogen-activated protein kinases in synaptic plasticity and memory. Curr Opin Neurobiol 14:311-317.

Taguchi Y, Koslowski M, Bodenner DL (2004) Binding of estrogen receptor with estrogen conjugated to bovine serum albumin (BSA). Nucl Recept $2: 5$.

Toran-Allerand CD (2005) Estrogen and the brain: beyond ER-alpha, ERbeta, and 17beta-estradiol. Ann N Y Acad Sci 1052:136-144.

Toran-Allerand CD, Guan X, MacLusky NJ, Horvath TL, Diano S, Singh M, Connolly ES Jr, Nethrapalli IS, Tinnikov AA (2002) ER-X: a novel, plasma membrane-associated, putative estrogen receptor that is regulated during development and after ischemic brain injury. J Neurosci 22:8391-8401.

Wade CB, Robinson S, Shapiro RA, Dorsa DM (2001) Estrogen receptor (ER)alpha and ERbeta exhibit unique pharmacologic properties when coupled to activation of the mitogen-activated protein kinase pathway. Endocrinology 142:2336-2342.

Walz R, Roesler R, Quevedo J, Sant'Anna MK, Madruga M, Rodrigues C Gottfried C, Medina JH, Izquierdo I (2000) Time-dependent impairment of inhibitory avoidance retention in rats by posttraining infusion of a mitogen-activated protein kinase kinase inhibitor into cortical and limbic structures. Neurobiol Learn Mem 73:11-20.

Watson CS, Norfleet AM, Pappas TC, Gametchu B (1999a) Rapid actions of estrogens in $\mathrm{GH} 3 / \mathrm{B} 6$ pituitary tumor cells via a plasma membrane version of estrogen receptor-alpha. Steroids 64:5-13.

Watson CS, Campbell CH, Gametchu B (1999b) Membrane oestrogen receptors on rat pituitary tumour cells: immuno-identification and responses to oestradiol and xenoestrogens. Exp Physiol 84:1013-1022.

Weatherman RV, Chang CY, Clegg NJ, Carroll DC, Day RN, Baxter JD, McDonnell DP, Scanlan TS, Schaufele F (2002) Ligand-selective interactions of ER detected in living cells by fluorescence resonance energy transfer. Mol Endocrinol 16:487-496.

Woolley CS (2007) Acute effects of estrogen on neuronal physiology. Annu Rev Pharmacol Toxicol 47:657-680.

Yokomaku D, Numakawa T, Numakawa Y, Suzuki S, Matsumoto T, Adachi N, Nishio C, Taguchi T, Hatanaka H (2003) Estrogen enhances depolarization-induced glutamate release through activation of phosphatidylinositol 3-kinase and mitogen-activated protein kinase in cultured hippocampal neurons. Mol Endocrinol 17:831-844.

Zhang HT, Zhao Y, Huang Y, Dorairaj NR, Chandler LJ, O’Donnell JM (2004) Inhibition of the phosphodiesterase 4 (PDE4) enzyme reverses memory deficits produced by infusion of the MEK inhibitor U0126 into the CA1 subregion of the rat hippocampus. Neuropsychopharmacology 29:1432-1439.

Zhao L, O’Neill K, Diaz Brinton R (2005) Selective estrogen receptor modulators (SERMs) for the brain: current status and remaining challenges for developing NeuroSERMs. Brain Res Rev 49:472-493.

Zurkovsky L, Brown SL, Korol DL (2006) Estrogen modulates place learning through estrogen receptors in the hippocampus. Neurobiol Learn Mem 86:336-343. 